\title{
Excited State Behavior of 1-(9-Anthryl)-2-(2-thienyl)ethene
}

\author{
Eun Ju Shin \\ Depanment of Chemisty, Sunchon Vational Linversity. Sumchon $540-7+2$. Sorea \\ Received Seprember t, 2002
}

Key Words : Diarylethene, Thiophene, Solvent effect, Fluorescence, l'hotoisonerization

Photochemistry and pholophy sics of diarylethenes ${ }^{1-1}$ have been cxicnsiycly studied because of the potential applicability in oplical memory and optoclectronic derices. The excited state properties of their nitrogen heleroaryl deriva1ives ${ }^{5-1]}$ have also becn investigated. However. the excited state behavior of diarylethenes bearing sulfur heterocyclic rings $^{1 \Sigma-1 \cdot 1}$ is much less known although special attention has been paid to 1.2-diarylethenes having thiopliene ring as photochromic molecules ${ }^{-1}$ in the last ten years because of their thermal and optical stability and fatigue resistance. We report here the preparation of trans-l-(9-antluryl)-2-(21hichyl)ethene ( $t-\mathrm{ATl} \mathrm{E})$, a thiophene derivative of trans-1(9-anthyyl)-2-phenylethene ( $t$-APE). and its absorption and fluorescence speciral data and photoisomerization belavior.

While stilbene shows very weak fluorescence due to very efficient two-way photoisomerization. ${ }^{l-1}$ relatively strong nuorescences are observed in trans-diarylelhenes containing large polyaromatic group such as anthracenc. which carry oul only one-way eis to rans photoisomerization. ${ }^{15-1:}$ The reason why trans-anthrylarylechenes are photochemically unreactive is duc to high activation barricr to twisting of $\mathrm{C}=\mathrm{C}$ bond by the localization of the excilation encrgy on large polyaromatic moicty.

Intramolecular charge transfer (ICT) processes have been extensively studicd for a number of donor- and acceptorcontaining compounds including stilbene derivatives. ${ }^{18-3]}$ ICT is cxpecied not only to make the fluorescence sensitive to the solvent polarity. but also to provide a way to lower the aclivation barricr to twisting of ethene bond in diarylethene containing large aromatic ring. Introduction of helcroaromatic ring into diarylellene increases the dipole moment of the compound to initiate the excited state ICT processes. ${ }^{\text {I] }}$ Photoisomerization reactions and rery neak fluorescence have been observed in polar solyent for N-licteroaromatic derivatives of $t$-APE. ${ }^{2-26}$ probably due to the contribution of the ICT statc. in comtrast that no photoisomerization and relatively strong fluorescence was obsened for $t$-APE itself. It is likely that ollicr helcroaromatic derivatives sucl as thiophene increases the donor-acceptor ability to favor the formation of the cxciled ICT state and leads to influence fluorescence and photoisomerization characleristics.

Absorption and fluorescence spectra of t-ATliE in cyclohexame and acclonitrile are shown and compared with those of $t$-APE and $t$-APyE in Figure 1. Table 1 summaries the lowest cxcited singlet state parameters of $t$-ATliE as well as $t$-APE and $t$-APyE. Absorption spectral shape and its maxima are similar for $t$-APE, $t$-APyE, and $t$-AThE and not nearly influenced by the solvent polarity as shown in Table 1 . However. the longest absorption bands of $t$-AThE and $t-$ APyE are similar to each other and are broader than that of a liydrocarbon molcculc. $t$-APE.

The situation is different for fluoresecnce spectra. In contrast to the absorption spectra. fluorescence spectra are greatly influenced by the heteroaromatics introduced in anthry lary lethenes and the solyent polarity for their intensity. or position. For a hydrocarbon t-APE, the fluorescence waxclength maxima and fluorescence quantum y icld are not so different in the solvents of different polarity. Howerer. the solvatochromic effect on the fluorescence spectra is obsenable for t-APyE. In accionitrilc. $t$-APyE shows large redshifl of $\mathrm{ca}, 17 \mathrm{~nm}$ and remarkable decrease of fluorescence
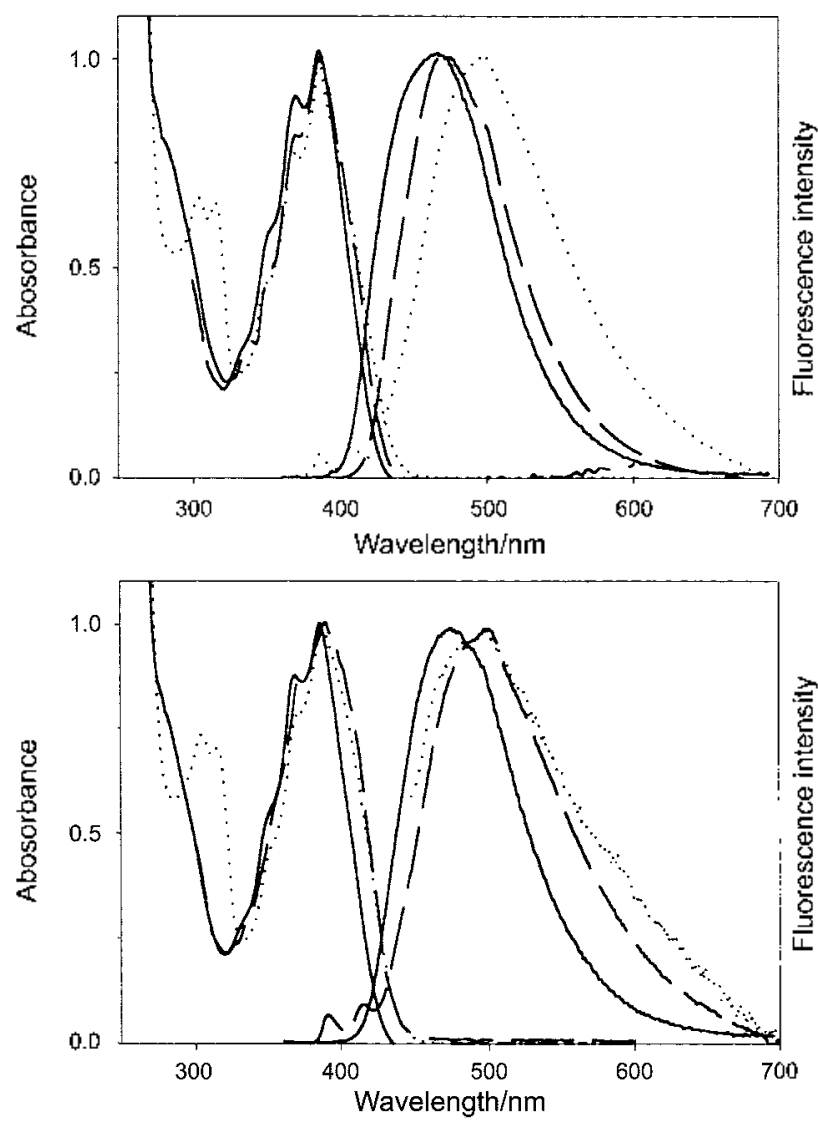

Fgure 1. Absotption and fluorescence spectra of $t-A P F$ (solid line) -APYL (dashed line). and t-AThl (dotted line) in cyclohexane (upper) and acetonitrile (lower). 
Table 1. Absorption and fluorescence data of $t-\Lambda P F, t-\Lambda P y F$, and t-AllzLi in crolowexine and acetonitrile

\begin{tabular}{|c|c|c|c|c|c|}
\hline Compound & Solvent & $\lambda_{\infty}^{\max } \operatorname{nm}$ & $\lambda_{f}^{\text {nax }}: \mathrm{nm}$ & $\Phi_{\mathrm{j}}$ & $\Phi_{1} x$ \\
\hline \multirow[t]{2}{*}{$1-\Lambda P]:^{a}$} & eyclohexaue & 385 & 468 & 0. 44 & 0.01 \\
\hline & acetonitrile & 385 & 476 & 0.45 & 0.6013 \\
\hline \multirow[t]{2}{*}{$\left.\left.1-\Lambda P_{Y}\right]\right]^{a}$} & eyclohexame & 386 & 476 & 0.44 & 0.01 \\
\hline & acetouitrile & 386 & 493 & 0.04 & 01.37 \\
\hline \multirow[t]{2}{*}{$\left.1-\Lambda \mathrm{T}]_{1}\right]:$} & cyclohexame & 387 & 502 & 0.28 & 0.01 \\
\hline & acetonitrile & 387 & 502 & 0.02 & 11.26 \\
\hline
\end{tabular}

"Diala from rel. 24.

Table 2. Absopption and lluorescence data of t-Allhe in various solvents

\begin{tabular}{|c|c|c|c|c|}
\hline Solvent & $\operatorname{lol}(30)^{\alpha}$ & $\lambda_{i}{ }^{m i L} \mathrm{~nm}$ & $\lambda_{f}^{\text {max }} \mathrm{nm}$ & $c b_{i}$ \\
\hline cyclohexane & 31.2 & 387 & 5012 & 11.28 \\
\hline toluene & 33.9 & 390 & 5112 & 0.24 \\
\hline telrahsdrofuran & 37.4 & 389 & 5012 & $(1.6) 72$ \\
\hline dichloromethane & 38.1 & 390 & 502 & 0.060 \\
\hline ethỵ] acetate & 41.1 & 388 & 498 & 0.080 \\
\hline acetonitrile & 46.0 & 388 & 502 & (). 015 \\
\hline ethemel & 51.9 & 387 & 502 & (). 144 \\
\hline methano] & 55.5 & 387 & $5(1) 2$ & 0.018 \\
\hline
\end{tabular}

"Dimrotls's empirical solvent polarity. parameter.

quantum yield relative to in cyclohexane (see Table 1). In nonpolar solvents. efficient fluorescence was observed. On the other hand. polar solvents result in the drastic reduction of fluorescence quantum yield. These results for $t$-APyE are probably due to the stabilization of intramolecular charge transfer (ICT) excited state in polar solvent. For $t$-AThE. even in cyclohexane. red-shifted fluorescence spectrum is observed relative to that of $t$-APE. But the solvatochromic shift of the fluorescence spectrum is not observed in contrast to $t$-APyE. $v i z$. fluorescence maximum of $t-\mathrm{AThE}$ in acetonitrile is the same as in cyclohexane. while the fluorescence quantum yield is greatly reduced in polar solvents. Absorption and fluorescence maxima and quantum yields of $t$-AThE are shown in Table 2 in various solvents. The above three compounds respond differently to the solvent polarity for fluorescence behavior, which are well compared in Figure 2.

For both $t$-AThE and $t$-APyE in polar solvents. it is inferred that ICT plays a role in causing $\Phi_{\mathrm{f}}$ to decrease, and opens other radiationless or reactive pathways. such as photoisomerization.

ln cyclohexane. $t$-AThE underwent no photoisomerization, similar to $t$-APE and $t$-APyE (see Table 1). In acetonitrile. photoisomerization of $t$-AThE upon irradiation is relatively efficient like $t$-APyE. On irradiation at $366 \mathrm{~mm}$. absorption spectral change of $t$-AThE is shown in Figure 3. When irradiated in acetonitrile, absorption spectrum of $t-\mathrm{AThE}$ becomes more stnictured and shows the decrease of its intensity d due to trans $\rightarrow$ cis photoisomerization. For $t-\mathrm{AThE}$ and $t-\mathrm{APYE}$ in acetonitrile, the decrease of the fluorescence quantum yields are compensated with the increase of the photoisomerization quantum yields contrast to those in

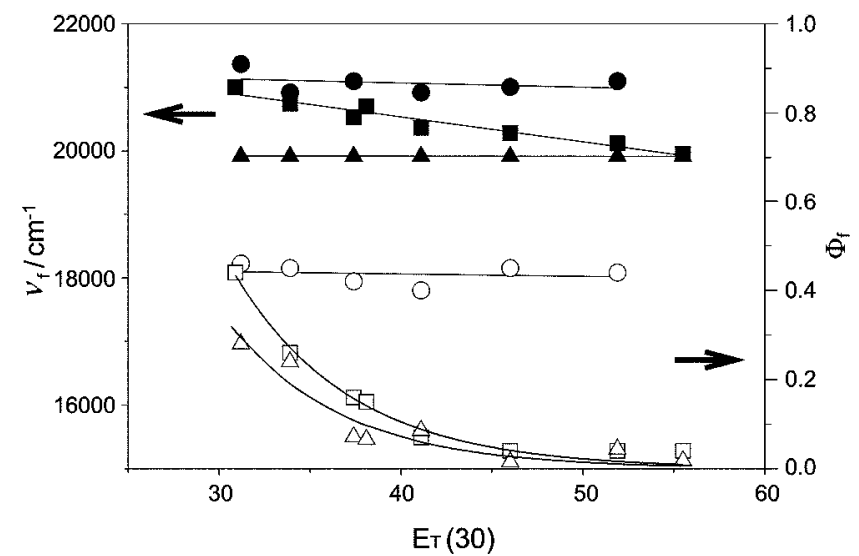

Figure 2. Dependence of thorescence maximum $v_{i}$ (closed symbol) and lluorescence quantum ficld $\Phi_{\mathrm{f}}$ (open stmbol) for $t$-APL (circle), t-APyE (rectangle), and -Althe (tringle) on the solvent polarity. $F_{T}(30)$ represents Dimroth s empirical solvent polarity parameter:

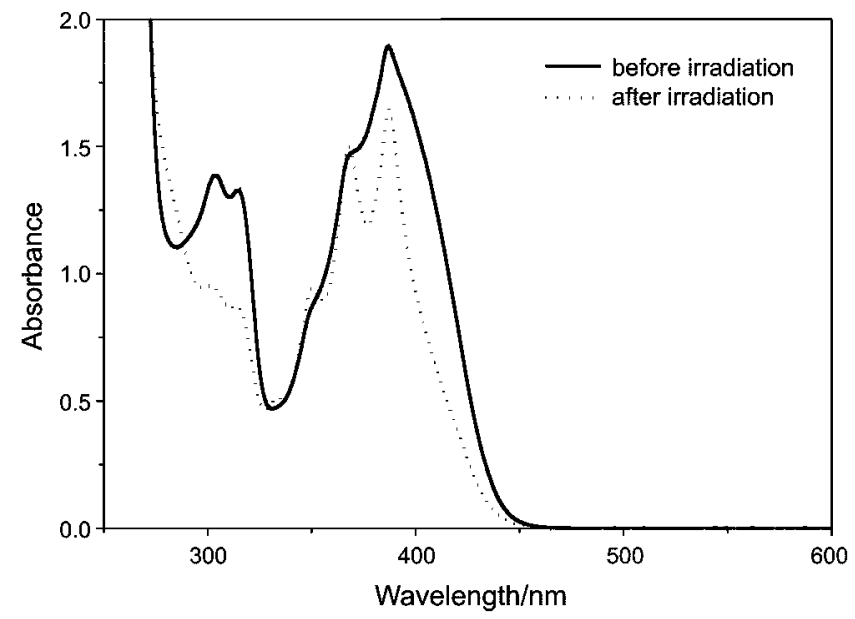

Figure 3. $\wedge$ bsorption spectral change of $t-\Lambda T h F$. in acetonitrile on irradiation at $.366 \mathrm{~nm}$.

cyclohexane remaining constant. as shown in Table 1. 1-(9Anthryl)-2-phenylethene, a hydrocarbon derivative without any heteroatom is well known to undergo no trans $\rightarrow c i s$ photoisomerization. The effect of introducing a heteroaryl ring such as thiophene and pyridine in $t$-APE can be explained by a contribution of the excited intramolecular charge transfer state to the photoisomerization behavior as well as the photophysical properties. $\Phi_{t \rightarrow c}$ of $t-\operatorname{AThE}(0.20)$ is lower than that of $t-\mathrm{APyE}(0.37)$ in acetonitrile. This reflects that a lower degree of intramolecular charge transfer character induced by less electronegative sulphur than nitrogen makes trans $\rightarrow$ cis photoisomerization less feasible.

In conclusion. the absorption and fluorescence and photoisomerization quantum yields of $t$-AThE were measured in cyclohexane and acetonitrile at room temperature. The observations in $t$-AThE are different with either $t$-APE or $t$ APYE. Both absorption and fluorescence maxima of $t$-AThE remain unchanged in various solvents. The fluorescence in polar solvents is extremely weak in contrast to moderate fluorescence quantum yield in nonpolar solvents. In cyclo- 


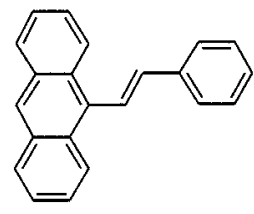

t-APE

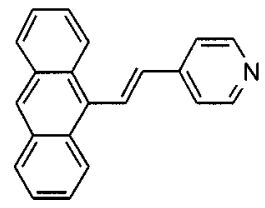

t-APyE

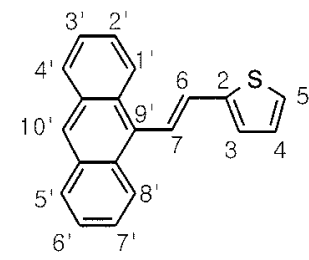

t-AThE
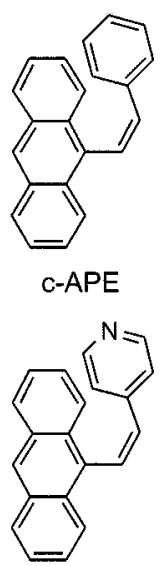

c-APyE

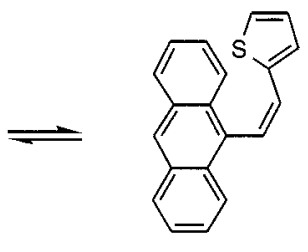

c-AThE
Scheme 1. Structures of APLi, APyL, and Alll:

hexane, a nonpolar solvent. efficient fluorescence was observed. while no photoisomerization was observed as tAPyE. Acetonitrile. a polar solvent. result in the drastic reduction of fluorescence quantum yield and increase of photoisomerization quantum yield similar to $t$-APyE. but no slift of fluorescence maximum in contrast to $t$-APyE.

\section{Experimental Section}

Matcrials trons-1-(9-Anthryl)-2-(2-thieny l)ethene (t-AThE) was prepared from Wittig coupling of 9-bromomethylantluracene $^{2.3}$ and 2-thiophenealdehyde. The structure was identified by $\mathrm{IR}$. 'H NMR. and mass spectra. t-AThE: yellow solid: IR 3049, 1619, 1440. 1261, 1093, 1018.959.808.738. $695 \mathrm{~cm}^{-1}$. ${ }^{1} \mathrm{H}$ NMR $\left(300 \mathrm{MHz} . \mathrm{CDCl}_{3}\right) \delta 7.06-7.11(2 \mathrm{H} . \mathrm{m}$. H4. 7). 7.23 (1H. d. $J=3.3 \mathrm{~Hz}, \mathrm{H} 3$ ). 7.31 (lH. d. $J=5.1 \mathrm{~Hz}$. H5). $7.46-7.50\left(+\mathrm{H}\right.$, dd. $\left.J=6 .+\mathrm{Hz} .3 .3 \mathrm{~Hz}, \mathrm{H} 2^{\prime} .3^{\prime}, 6^{\circ} .7^{\prime}\right)$. $7.77(1 \mathrm{H} . \mathrm{d} . J=16.5 \mathrm{~Hz} . \mathrm{H} 6) .8 .00-8.03(2 \mathrm{H} . \mathrm{dd} . J=6.4 \mathrm{~Hz}$. $3.3 \mathrm{~Hz}, \mathrm{H} 4,5) .8 .3+-38(2 \mathrm{H}, \mathrm{dd}, J=6 .+\mathrm{Hz}, 3.3 \mathrm{~Hz} . \mathrm{HI}$ ', $8^{\circ}$ ). 8.40 (1H, s. $\mathrm{HlO} 0^{\circ}$ ). MS m/e 286 (M). c-AThE: pale yellow solid: 'H NMR $\left(300 \mathrm{MHz}, \mathrm{CDCl}_{3}\right) \delta 6 .+2(1 \mathrm{H} . \mathrm{d} . J=$ $5.9 \mathrm{~Hz}, \mathrm{H} 7) .6 .88-6.98(2 \mathrm{H}, \mathrm{m} . \mathrm{H} 3.4) .7 .15$ (lH. d. $J=4.6$ Hz. H5). $7.40-7.50\left(5 \mathrm{H}, \mathrm{m} . \mathrm{H} 22^{\circ} .3^{\circ}, 6^{\circ} .7,10^{\circ}\right) .7 .64(\mathrm{lH} . \mathrm{d}$. $J=5.9 \mathrm{~Hz}, \mathrm{H} 6) .8 .00-8.03(2 \mathrm{H} . \mathrm{dd}, J=6.4 \mathrm{~Hz} .3 .3 \mathrm{~Hz}, \mathrm{H} 4$. $\left.5^{\circ}\right) .8 .18-22\left(2 \mathrm{H}\right.$. dd. $\left.J=6.4 \mathrm{~Hz} .3 .3 \mathrm{~Hz} . \mathrm{Hl}^{\circ} .8^{\circ}\right)$. MS m/e $286(\mathrm{M})$.

Spectroscopic and Photochemical Measurements. IR spectra were obtained in $\mathrm{KBr}$ pellets on Midac Prospect-IR spectrometer. 'H NMR spectra were measured on a 300 $\mathrm{MHz}$ Bnuker DRX300 in chloroform- $c_{1}$. Mass spectra were obtained on Micromass Platform II GC-MS spectrometer.
Absorption spectra were recorded on a Slimadzu UV$240 \mathrm{IPC}$ spectrophotometer. Steady-state fluorescence spectra were recorded on an SLM-Aminco AB2 luminescence spectrophotometer. The concentrations were controlled to be $c a .1 \times 10^{-5} \mathrm{M}$. where the absorbances of the solutions at the excitation wavelength of $360 \mathrm{~lm}$ were usually at the value of $0.07-0.08$. to avoid inner filter effects. Fluorescence quantum yields $\left(\Phi_{i}\right)$ were determined using quinine bisulfate as a standard $\left(\Phi_{1}=0.55\right.$ in $\left.0.1 \mathrm{M} \mathrm{H}_{2} \mathrm{SO}_{.}\right) .^{-2}$ For the detemuination of photoisomerization quantum yield. irradiation wavelength of 366 run isolated with Corning glass filters (CS 0-52 and 760) was employed in argon-saturated solution using a homebuilt merry-go-round system equipped with a Hanovia 450W medium-pressure $\mathrm{Hg}$ arc lamp. Potassium ferrioxalate was used for chemical actinometry. ${ }^{27}$ Concentration for the measurements of quantum yield of photoisomerization was adjusted to be $c a .8 \times 10^{-4} \mathrm{M}$ in which all incident light was absorbed. Quantitative analyses of the trans $\rightarrow$ cis photoisomerization reaction were carried out by HPLC at a flow rate of $1 \mathrm{~mL} \mathrm{~min}{ }^{-1}$ using methanol as an eluent. HPLC was accomplished using Merck LiChrosorb RP-18 analytical column on a Spectra-Physics SP precision isocratic pump, a Spectra 100 variable wavelength detector, and a SP4290 integrator.

Acknowledgment. The author would like to thank Mr. S. H. Lee and Mr. S. H. Joo for their technical assistance and KBSI for their help in the measurement of NMR and mass spectra. This work was supported by a grant No. R04-2002$000-0001+-0$ (2002) from Korea Science \& Engineering Foundation.

\section{References}

1. Saltiel. I.: Charlton. I. I. In Rearmgements in Grond and Excited Staks, de Mayo. P.. Fd.: Academic Press: New York. 1980.

2. Waldeck. D. H. (hen. Ren: 1991. 9/. 415.

3. Meier. H. Lngen! Chent Int Fd Fingl. 1992.31. 1399.

4. Irie. M. (Them. Reve 2000. 100. 1685.

5. Mazzucato, U. Pme Appl. Chem. 1982, 54, 1705.

6. Marconi, G.: Bartocei. G.: Mazzucato. U.: Spalletti, A.: Abbatc, F.: Angeloni, J.: Castellucei, F. Chem. Phys. 1995. 196, 38.3.

7. Mazatcato. U.: Momicchioli. F. (he'm. Rev 1991. 91. 1679.

8. Shim. S. C.: Kim. M. S.: Lee. K. T.: Lee. B. H. . Photochtem. Photobiol.1. Chem 1992.65. 121.

9. Grummt, U.-W.: Birekner, F.: I indauler, II.: Beck, B.: Rotomskis, R. J. Photochem Ihofobiol .t: Chem 1997. 104. 69 .

10. 7.han, C.-I..: Wang. D.-Y. J. Photochem. Phototiol t: Chem. 2002. $1+7.93$.

11. Wang. S.-L.: Ho. T.-I. J. Photochem Photohiol t 2000 . /35. 119.

12. Song. K.: Wu, I..-7.: Yang. C.-II.: Tung. C.-II. Tet. Leth 2000. 1951

1.3. Bartocei, G.: Spalletti, A.; Becher. R. S.: Flisei, F.: Floridi. S.: Mazulcato. U. . . 1m. Chem. Soc. 1999. 121. 1065.

14. Gajdek. P.: Becker. R. S.: Elisei. F.: Mazzucalo. U.: Spalletli. A. J. Photoch'm. Photobiol. 1 1996. 100. 57.

15. Arai, T.: Tokumanu, K. fdt Photochem 1995, 20. 1

16. Göner, It.; Kulm, It. fta: Photochem 1995, 19.1

17. Aloisi, G. G.: Flisci, F.: I attcrini, I .: Mazancato, U.: Rodgers. M. A. J. J. . W (Wem. Soc. 1996. MS. 10879 . 
18. Grabonshi. L. R. Pme Appl. Chem. 1993, 65, 1751.

19. Hasthmolo. M.: Hamaguchi. H. J. Phys. (hem. 1995, 99. 7875.

20. Scherer. 1.: $\operatorname{van}$ Stohkum. 1. H. M.: Brouwer. A. M.: Verhoeven. .. W. J. Phos. Chem. 1994, 98, 10539.

21. Rettig. W. Appl Phos. B 1988. 45. 145.

22. Shim, E. J.: Bae, J. Y.: Kim. S. I.: Kang. II. K.: Shim, S. C. $J$. Photochem. Photohiol. 1 1997. 107. 137.
23. Shin. E. I.: Choi. S. W. J. Photochem. Photobiol il 1998. 11+. 23.

24. Shin. E. I. Bull. Sorean (hem. Soc 1999. 20. 1263.

25. Shin. E. I.: Lee. S. H. Bull. Korean (hem Soc. 2002. 23. 1309.

26. Shin, Г. J.: Stackow R.: Foote. C. S. Hhws. Chem. Chkm. Phys. 2002, 4. 5088 .

27. Calvert. J. G.: Pitts, Jr.. J. N. Ihotochemismy: Wiley: Now York. 1966. 